\title{
Immunosuppression-related neurological disorders in kidney transplantation
}

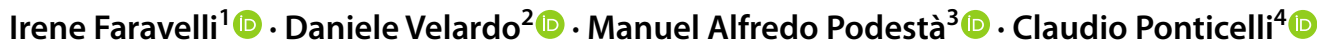

Received: 8 July 2020 / Accepted: 27 December 2020 / Published online: 22 January 2021

(c) The Author(s) 2021

\begin{abstract}
A large number of neurological disorders can affect renal transplant recipients, potentially leading to disabling or lifethreatening complications. Prevention, early diagnosis and appropriate management of these conditions are critical to avoid irreversible lesions. A pivotal role in the pathogenesis of common post-transplant neurological disorders is played by immunosuppressive therapy. The most frequently administered regimen consists of triple immunosuppression, which comprises a calcineurin inhibitor (CNI), a purine synthesis inhibitor and glucocorticoids. Some of these immunosuppressive drugs may lead to neurological signs and symptoms through direct neurotoxic effects, and all of them may be responsible for the development of tumors or opportunistic infections. In this review, after a brief summary of neurotoxic pathogenetic mechanisms encompassing recent advances in the field, we focus on the clinical presentation of more common and severe immunosuppression-related neurological complications, classifying them by characteristics of urgency and anatomic site. Our goal is to provide a general framework that addresses such clinical issues with a multidisciplinary approach, as these conditions require.
\end{abstract}

Keywords Immunosuppressive drugs $\cdot$ Nervous system $\cdot$ Neurological disorders $\cdot$ Renal transplantation

\section{Introduction}

A wide array of neurological complications may impact on the outcome of renal transplant recipients, possibly leading to disabling or life-threatening diseases. Some of these complications are caused by the disorders that led to transplantation and by dialysis [1]. Since criteria to admit donors and recipients to a transplantation program have been considerably expanded in recent years, elderly individuals and patients with severe comorbidities may now be considered suitable candidates for kidney transplantation. On one hand, this has

Irene Faravelli

irene.faravelli@unimi.it

1 Neuroscience Section, Department of Pathophysiology and Transplantation (DEPT), Dino Ferrari Centre, Università degli Studi di Milano, Milan, Italy

2 Neurology Unit, Foundation IRCCS Ca' Granda Ospedale Maggiore Policlinico, Milan, Italy

3 Renal Division, ASST Santi Paolo e Carlo, Department of Health Sciences, Università degli Studi di Milano, Milan, Italy

4 Milano, Italy allowed to expand the number of recipients and donors, but on the other it has increased the risk of extra-renal complications, including those affecting the central and peripheral nervous system.

The most crucial role in the pathogenesis of post-transplant neurological disorders is played by immunosuppressive drugs. The choice of immunosuppressive regimens varies widely across transplant programs, nevertheless, the most frequently adopted schedule rests on triple immunosuppression comprising a calcineurin inhibitor (CNI) such as tacrolimus (TAC) or cyclosporine (CsA), a purine synthesis inhibitor, such as mycophenolate (MPA) or azathioprine, and glucocorticoids. Some centers have been gaining experience with inhibitors of the mammalian target of rapamycin (mTOR) and, more recently, with belatacept. Antithymocyte globulins (ATG), anti-CD52 (alemtuzumab), anti-CD25/IL-2R (basiliximab) and anti-CD20 (rituximab) monoclonal antibodies are also frequently used for induction therapy or treatment of rejection episodes. The proteasomeinhibitor bortezomib has also been used for the management of antibody-mediated rejection in selected cases. Some of these immunosuppressive drugs may exert direct neurotoxic 
effects, and all of them may be involved in the development of tumors or opportunistic infections [2].

In this review, after a brief overview of neurotoxic pathogenetic mechanisms encompassing recent advances in the field, we focus on the clinical presentation of more common and severe neurological complications. This work deals with the neurological presentations most frequently caused by treatment with immunosuppressive drugs,

Central NS
- Seizures
- PRES
- Infections
- Psychiatric disorders
- PTLD
- Stroke$$
-
$$

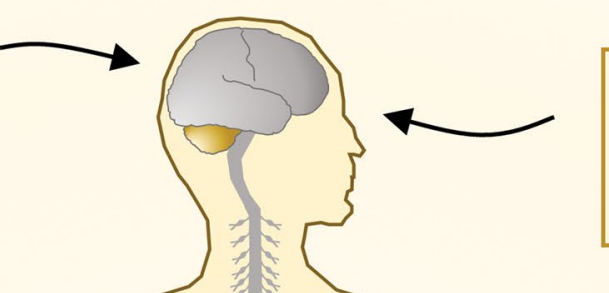

Eye and Ear

- Optic neuropathy

- Hearing loss

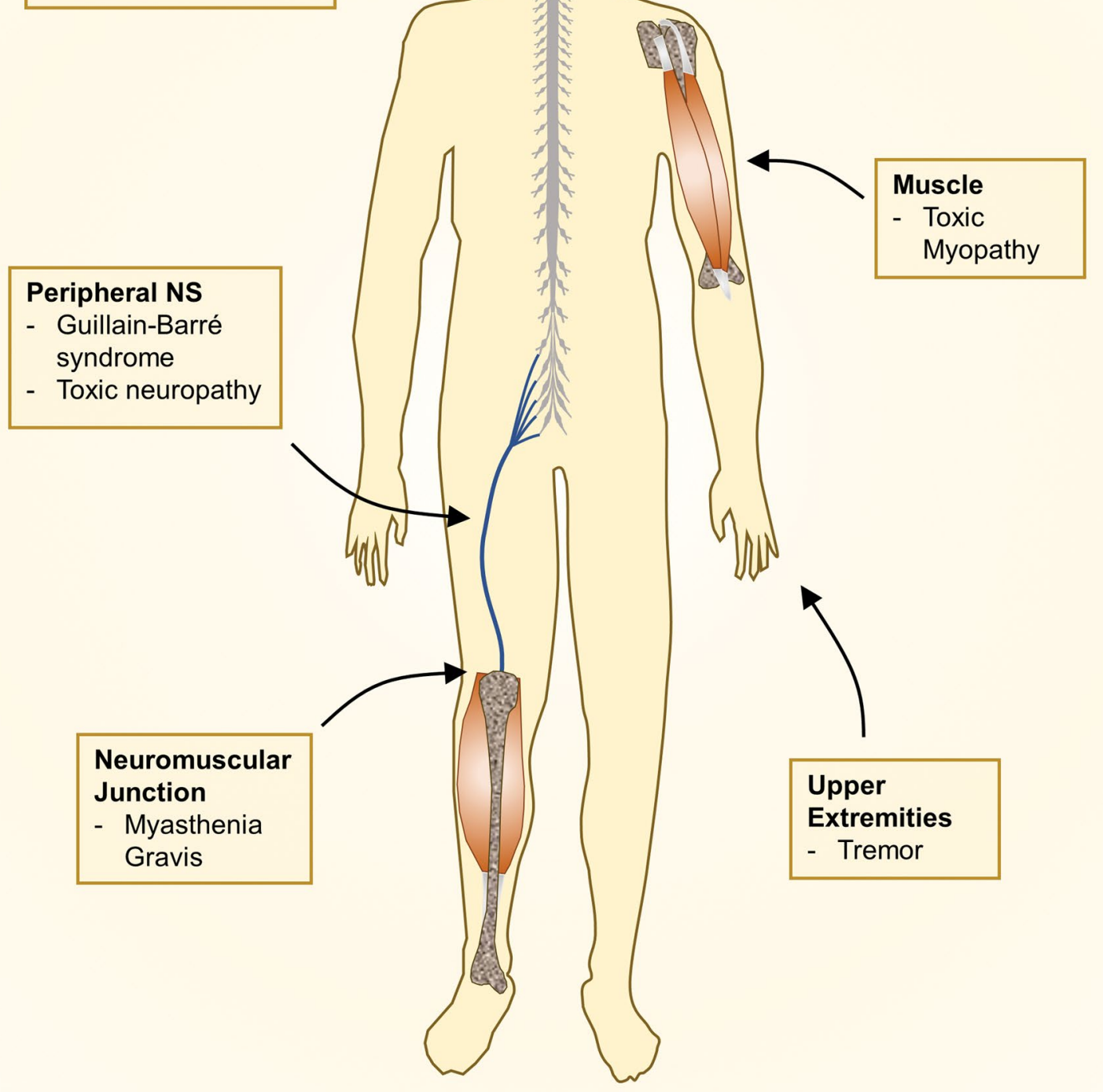

Fig. 1 Neurological complications in renal transplant recipients by anatomic site. NS nervous system, PRES posterior reversible encephalopathy syndrome, PTLD post-transplant lymphoproliferative disorders 
classifying them by characteristics of urgency and anatomic site (central or peripheral nervous system) (Fig. 1).

\section{Direct effects of immunosuppressive drugs}

\section{Calcineurin inhibitors}

Calcineurin is a calcium- and calmodulin-binding protein phosphatase that participates in a wide array of cellular processes and calcium-dependent signal transduction pathways, including T-cell activation. CsA and TAC inhibit calcineurin to a similar degree, inducing downstream blockade of IL-2 signaling, ultimately interfering with T-cell activation, proliferation and differentiation. Calcineurin is highly expressed in the central nervous system, particularly in neurons vulnerable to ischemic and traumatic injury.

Several mechanisms may be involved in CNI-related toxicity on the central nervous system (CNS) (Fig. 2). CNIs do not readily cross the blood-brain barrier (BBB) in physiological states, however, these agents may induce apoptosis of brain capillary endothelial cells and inhibit
P-glycoprotein (P-gp) function, thus altering BBB permeability [3, 4]. These effects are particularly relevant when other, concomitant causes of BBB permeability alteration are present (e.g. inflammation). After diffusing across the BBB, CNIs may exert selective toxic effects on glial cells [5] and oligodendrocytes [6], the latter being particularly susceptible to CNI-induced damage due to their high calcineurin content. CNIs may also directly alter mitochondrial function, increasing oxidative stress in glial cells [7]. Moreover, both CsA and TAC modulate the activity of excitatory and inhibitory neurotransmitter receptors $[8,9]$, leading to altered excitability properties and resulting in membrane depolarization, which have been proposed as an additional mechanism of CNI neurotoxicity [10].

In addition to their direct effects on neural cells, CNIs may lead to activation of the major vasoconstriction systems, i.e. the renin-angiotensin and endothelin systems, and increase sympathetic system activity. In addition, CNIs inhibit nitric oxide synthesis and nitric oxide-mediated vasodilation. Altogether, these processes cause vasoconstriction and endothelial dysfunction [11], which result in systemic hypertension, local ischemia and cerebral edema. Moreover, if endothelial integrity is disrupted, CNIs may damage

Fig. 2 Proposed mechanisms of neural toxicity due to calcineurin inhibitors (CNIs). Blood-brain barrier (BBB) permeability can be altered by CNI-induced damage to the capillary endothelium or by other concomitant disorders (e.g. infection and inflammation). CNI crossing of the damaged BBB may lead to altered neuronal excitability and could result in direct toxicity on glial cells (astrocytes and oligodendrocytes), which are particularly susceptible to these agents due to their high calcineurin content

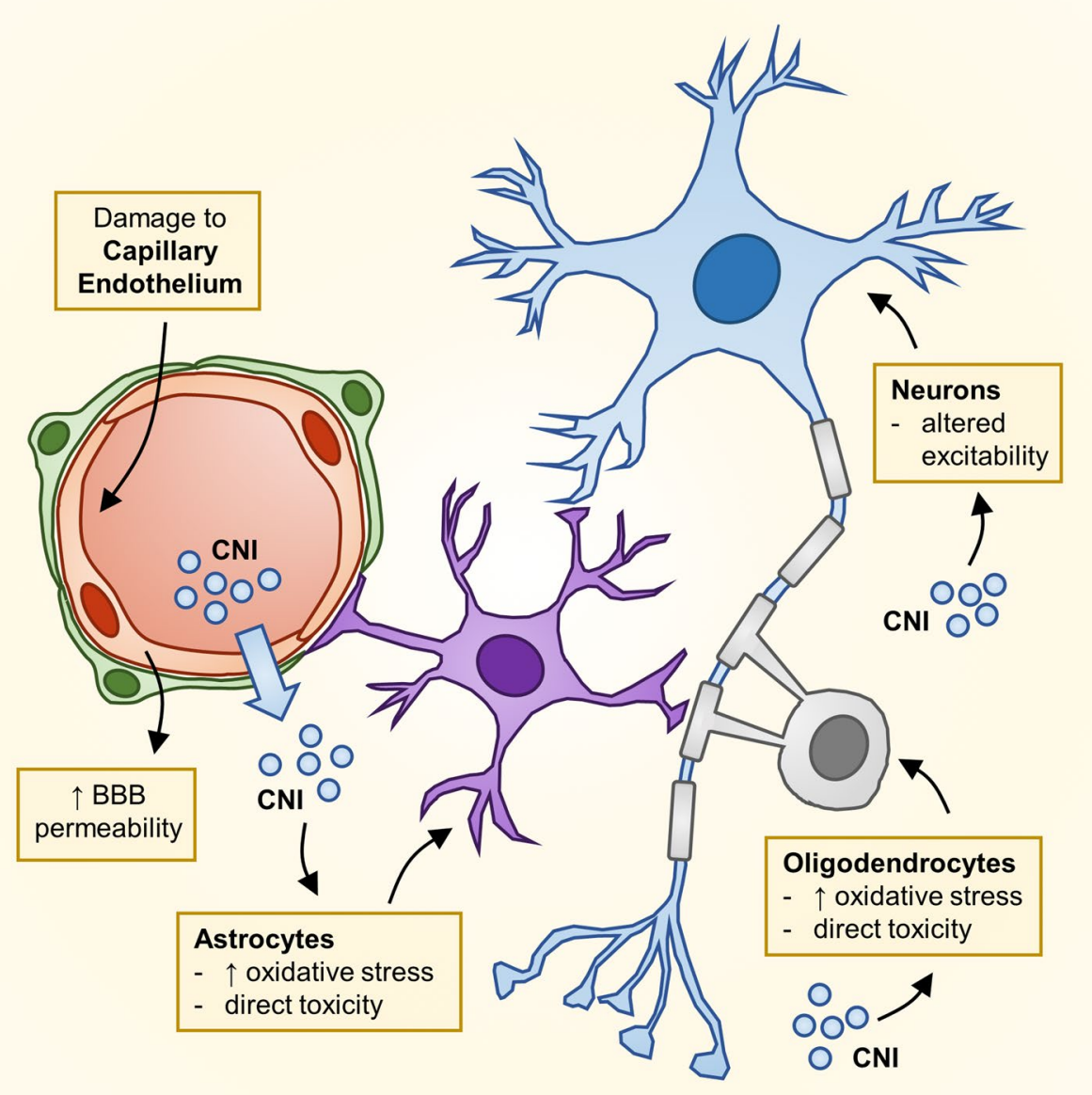


astrocytes that provide structural, trophic and metabolic support to neurons. On the other hand, animal models have suggested that CsA may prevent brain damage from forebrain ischemia when allowed to pass the BBB, whereas TAC is significantly less effective [12-16]. This neuroprotective effect might reflect inhibition of cyclophilin $\mathrm{D}$, but the exact mechanism and its clinical potential still need to be fully elucidated [17].

\section{Purine synthesis inhibitors}

Azathioprine and mycophenolate interfere with nucleotide synthesis with different mechanisms. Azathioprine is a mercaptopurine prodrug, whose pharmacological activity rests on the formation of two active intracellular nucleotides: thioinosinic acid inhibits the de novo pathway of purine synthesis, while 6-thioguanine interferes with the purine salvage pathway. These actions result in depletion of cellular purine stores and inhibition of DNA/RNA synthesis, hampering lymphocyte proliferation. The immunosuppressive effects of azathioprine are more potent on T cells compared to $\mathrm{B}$ cells, owing to intrinsic metabolic differences in these cells. Mycophenolate salts are prodrugs releasing active mycophenolic acid (MPA), which reversibly inhibits inosine monophosphate dehydrogenase and results in a marked reduction of guanosine triphosphate necessary for DNA synthesis. Neurological symptoms directly induced by purine synthesis inhibitors are rare and mild, usually manifesting as depression and headaches. Cases of progressive multifocal leukoencephalopathy (PML), caused by John Cunningham Virus (JCV) infection, have been reported in renal transplant recipients or lupus patients treated with MPA, and thus the Food and Drug Administration warned against this possible risk.

\section{Glucocorticoids}

Synthetic glucocorticoids exert a wide array of anti-inflammatory and immunosuppressive activities that are mainly mediated by their genomic effects. Glucocorticoids bind to their specific cytosolic receptors, enter the nucleus and either activate response elements that induce anti-inflammatory genes, or repress inflammatory transcription factors (e.g. NF-kB or activator protein-1). These drugs may also produce non-genomic effects with rapid onset and short duration, whose mechanism of action is incompletely understood. At least part of this activity seems to be mediated by membrane receptors that can modulate anti-inflammatory and antioxidant effects [18].

Brain cells express two types of corticosteroid receptors, i.e. mineralocorticoid and glucocorticoid receptors, which differ in distribution and affinity and can exert modulatory effects on a variety of brain functions from early development through late life. The potential effects of glucocorticoids on neuronal activity are determined predominantly by receptor distribution since glucocorticoids easily pass the BBB and virtually reach all brain cells, although local enzymatic conversion and the degree of cell accessibility contribute to the actual intracellular concentration [19].

The use of glucocorticoids in pediatric transplant recipients may be particularly problematic. Exposure to high-dose glucocorticoids in early life can significantly affect the hypothalamic-pituitary-adrenal axis and increase the susceptibility to develop metabolic, neuropsychiatric and neurodegenerative disorders [20]. In addition, elevated glucocorticoid levels and prolonged exposure to stressful conditions can induce structural remodeling of neurons with synaptic loss and maladaptive alterations in glial functions [21].

\section{mTOR inhibitors}

Sirolimus (rapamycin) and its derivate everolimus inhibit the mTORC1 complex, a master regulator of cell growth and metabolism, interfering with signals leading to T-cell proliferation. Both mTOR inhibitors can cross the BBB, but there is considerable uncertainty regarding their potential neuroprotection or neurotoxicity. In the nervous system, the mTOR pathway regulates axonal sprouting, axonal regeneration and myelination, ion channel and receptor expression, as well as dendritic spine growth [22]. mTOR signaling can also regulate mitochondrial function [23] and enhance synaptic activity by promoting the synthesis and surface expression of AMPA receptors, which are members of the ionotropic class of glutamate receptors [24]. On the other hand, chronic activation of mTOR signaling can aggravate vascular senescence and ischemic injury, and may contribute to neuroinflammation and autophagy dysfunction in degenerative neurological diseases [25]. In addition, mTOR is involved in the upregulation of glutamate transporter 1 that is linked to several neuronal disorders such as stroke, Alzheimer's disease, and amyotrophic lateral sclerosis [26]. Accordingly, mTOR inhibitors are not considered neurotoxic drugs per se, and may even play a neuroprotective role by suppressing the pharmacological effects of the mTOR pathway. However, some data suggest that sirolimus could enhance CsA-induced formation of reactive oxygen species and their negative metabolic effects in brain cells, while everolimus seems to antagonize CsA effects [27].

\section{Other immunosuppressive agents}

Rituximab is a monoclonal antibody with a high affinity for the CD20 antigen, a membrane protein expressed on B cells. Reports of PML cases in patients treated with Rituximab have raised concerns about its use in renal transplant recipients, since the risk seems to be higher in patients treated 
with multiple immunosuppressive drugs [28]. However, the incidence of this potentially fatal complication seems to be very low both in patients with autoimmune disorders and in renal transplant recipients $[29,30]$. Alemtuzumab is a humanized anti-CD52 monoclonal antibody that is used as induction or anti-rejection therapy in renal transplant recipients. Though alemtuzumab and other T cell-depleting drugs have not been conclusively demonstrated as a direct cause of neurotoxicity, they have a profound impact on the immune system, and may therefore predispose to infections and their neurological complications in the transplantation setting [31].

Rabbit ATG are polyclonal antibodies that reduce the number of circulating $\mathrm{T}$ cells through cell lysis. Bortezomib, a broad-spectrum proteasome inhibitor, may cause neurotoxic effects through a dysregulation of neurotrophins and blockade of nerve growth factor-mediated neuronal survival induced by NF- $\mathrm{\kappa B}$ inhibition. Belatacept is a fusion protein with high affinity for CTLA-4 (CD152), a cell surface protein transiently expressed on $\mathrm{T}$ cells that attenuates their activation. This drug blocks T-cell costimulation and may increase the risk of post-transplant cerebral lymphoma in Epstein Barr virus- (EBV) negative patients who receive a kidney from EBV positive donors [32]. Finally, Eculizumab, a monoclonal antibody that binds to the terminal complement component $\mathrm{C} 5$ and blocks its activating cleavage, is currently used in renal transplant recipients diagnosed with atypical hemolytic uremic syndrome; complement inhibition can increase the risk of infection by capsulated bacteria (e.g. S. pneumoniae, N. meningitidis), which can be however effectively prevented by vaccination against these pathogens.

\section{Central nervous system}

\section{Acute clinical presentations}

\section{Seizures}

Seizures have been reported in 6-36\% of transplant recipients [33] and the most frequent causes include immunosuppressive drugs. CsA is epileptogenic and responsible for seizure in $2-6 \%$ of patients, while TAC has been associated to seizures with a slightly higher frequency (5-11\%) [34]. A study evaluating 132 patients who underwent kidney transplantation described seizures in $16.7 \%$ of them, none of whom had a prior history of seizures [35]. It is worth mentioning that some of these studies report higher CNI targets, which can contribute to the increased risk of seizure. However, seizures may occur even with actual standard doses of CNI, especially in pediatric patients with underlying metabolic abnormalities (hyponatremia, hypomagnesemia, hypoglycemia) and infections.
Intravenous methylprednisolone pulses (MPP), 500-1000 mg per dose, are the standard treatment for acute rejection and are frequently used for induction therapy. Although MPP therapy may be considered for possible treatment in patients with focal epilepsy, exceptional cases of seizures have been reported after intravenous administration of steroids [36]. Complications occurred in severely affected patients and when treatment was injected rapidly and through a central venous line. To minimize the neurological side-effects of intravenous high-dose MPP, they should be infused in a peripheral vein over 30-60 min and outpatients should be monitored for at least $2 \mathrm{~h}$ after infusion [37].

\section{Stroke}

Several studies have consistently reported a higher frequency of cerebral vascular events in kidney transplant recipients compared to the general population, with an incidence of $5 \%$ in the first year and $9.4 \%$ in the second year post-surgery [37-39]. This is in part due to predisposing factors such as vasculopathy, accelerated atherosclerosis, hypertension and diabetes, which are among the most frequent causes of end-stage renal disease and are further exacerbated by maintenance dialysis. Diabetes and age $>40$ years have been described as major risk factors for stroke occurrence after transplantation, and kidney recipients may also present posttransplant polycythemia with consequent hypercoagulability [40]. Moreover, mTOR inhibitors, CsA (and TAC to a lesser extent) may contribute to worsening dyslipidemia, thus increasing the risk of ischemic stroke [41, 42]. CNIs and steroids can also be responsible for hypertension (CsA more than TAC) and diabetes (TAC more than CsA) development or worsening, which represent leading causes of both ischemic and hemorrhagic cerebral events [43, 44]. In general, transplant patients suffer from an increased risk of ischemic rather than hemorrhagic events, but mortality is higher with the latter. The risk of aneurysm rupture and subarachnoid hemorrhage is increased in patients with a diagnosis of autosomal dominant polycystic kidney disease. Proper management of established risk factors is crucial in the follow-up of kidney transplant recipients, with routine carotid artery assessment by Doppler imaging playing a pivotal role.

\section{Posterior reversible encephalopathy syndrome}

Posterior Reversible Encephalopathy Syndrome (PRES) is a severe neurological complication caused by vasogenic edema, which can lead to permanent deficits when not properly identified and treated [45]. It usually affects the posterior cerebral circulation and the clinical presentation can include nausea, headache, visual impairment, 
seizures and consciousness alteration. Recently identified alternative presentations involve spinal cord PRES, subacute diencephalic angio-encephalopathy, as well as posterior fossa edema and hydrocephalus [45]. Common radiological lesions are localized to the parieto-occipital or posterior frontal cortical-subcortical regions, and are usually reversible [46]. Management is based on blood pressure control, supportive therapy and correction of electrolyte disorders, especially magnesium ones. Rapid withdrawal of the offending drug appears to prevent complications and hasten recovery [47]. Antiepileptic drugs should be used to treat seizures, keeping in mind that these drugs activate CYP450 and may reduce the bioavailability of glucocorticoids and CNIs. In particular, valproic acid, fosphenytoin and carbamazepine use may result in both enzymatic and protein displacement [48]. Safer alternatives with regard to their drug interaction potential may be represented by Levetiracetam, Gabapentin, Pregabalin and Lacosamide [49]. Anesthesia and mechanical ventilation should be instituted in generalized status epilepticus. Most frequently, immunosuppressant-related PRES occurs within the first year after transplantation (mostly in the first month), even though late-onset cases have been described [50]. CNIs are the immunosuppressive drugs most frequently associated with PRES development through brain endothelial and astrocyte damage [51]. CNIs have been shown to cause PRES even at therapeutic serum concentrations and without concomitant hypertension. However, cases of PRES related to rituximab and mTOR inhibitor treatment have also been reported [52, 53].

\section{Acute and subacute clinical presentations}

\section{Infections}

Central nervous system infections are extremely frequent in renal transplant recipients, and represent $9-10 \%$ of all neurological complications in this population [54]. The subtle clinical presentation typically displayed by these patients can hinder prompt diagnosis and timely treatment, both of which are crucial to prevent a fatal evolution. Indeed, immunosuppressive drugs, due to their anti-inflammatory effects, can alter meningeal signs and clinical features typical of CNS infections. Patients may only report mild symptoms like headache, fever and confusion, which can abruptly evolve to focal neurological deficits and consciousness impairment. Thus, transplant recipients should be evaluated with a lower threshold for suspecting CNS infections compared to the immunocompetent population. In addition, CNS infections can be unusually severe in these patients, making prompt recognition and pathogen identification crucial.

To narrow down the exceptionally broad differential diagnosis of responsible infectious agents, time from transplantation should always be considered since specific pathogens are more likely to be responsible at different time points (Table 1). In the first month, nosocomial or pre-existing pathogens (e.g. latent tuberculosis reactivation) are most likely to be identified. During this timeframe, transplantation recipients may also suffer from donor-derived infections. The infectious risk is highest from one month to six months after transplantation, when doses of immunosuppressive drugs are higher and atypical pathogens are more prevalent. Fungal and viral opportunistic infections are more frequent: among these, cytomegalovirus (CMV) is the most common (up to $8 \%$ of renal graft recipients) and may cause meningeal and retinal complications. Many transplant centers recommend CMV prophylaxis with valacyclovir or ganciclovir in highrisk patients such as seronegative recipients who receive a graft from seropositive donors and/or patients treated with $\mathrm{T}$ cell-depleting antibodies. Other centers prefer to start preemptive treatment when signs of virus replication are found before CMV disease develops [55]. Fungal infections are less frequent, but they are burdened by a high mortality rate, with cryptococcus neoformans displaying the highest incidence in this category [56].

Six months after transplantation, the infection risk starts to decrease and the most frequently encountered pathogens are EBV, Cryptococcus neoformans and JC virus, that can lead to PML, which is a fatal neurological condition characterized by subcortical white matter lesions with different neurological manifestations and without any effective treatment [57]. Nivolumab, a monoclonal antibody against PD-1 (programmed death-1), failed to obtain any improvement in transplant recipients [58], although stopping or reducing immunosuppressive drugs was successful in some cases [59]. Notably, infusion of allogeneic BK virus-specific T cells achieved alleviation of clinical signs and clearance/ reduced load of JC virus in the cerebrospinal fluid (CSF) in two immunosuppressed patients [60].

The work-up for CNS infection is based on lumbar puncture, blood cultures and brain imaging. Cerebrospinal fluid analyses should include glucose and protein concentration, polymerase chain reactions for a comprehensive panel of viral and mycobacterial nucleic acids, cryptococcal antigen, cytology and microbiological cultures. Whenever available, contrast-enhanced MRI is the preferred radiological exam, since it can highlight leptomeningeal enhancement, parenchymal inflammation and potential abscesses.

It is important to rule out the cytokine-release syndrome as a differential diagnosis, since its manifestations can resemble those of CNS infection with vomiting, fever and seizures. This is a rare but severe systemic inflammatory response due to initial immune system activation after treatment with antilymphocyte antibodies (e.g. Rituximab, Alemtuzumab and ATG), used for induction or anti-rejection therapy [61]. These serious side effects are more frequent 


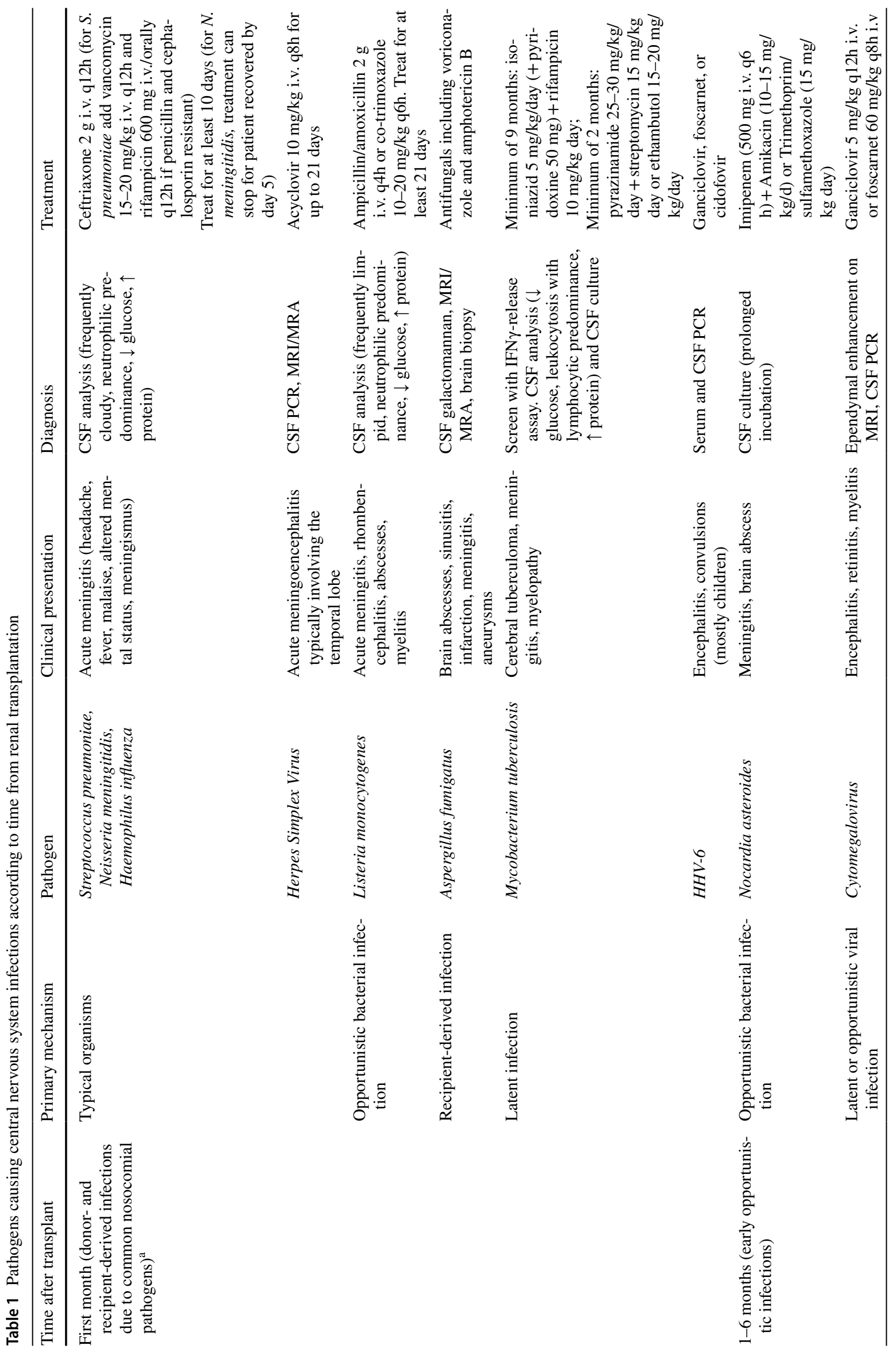




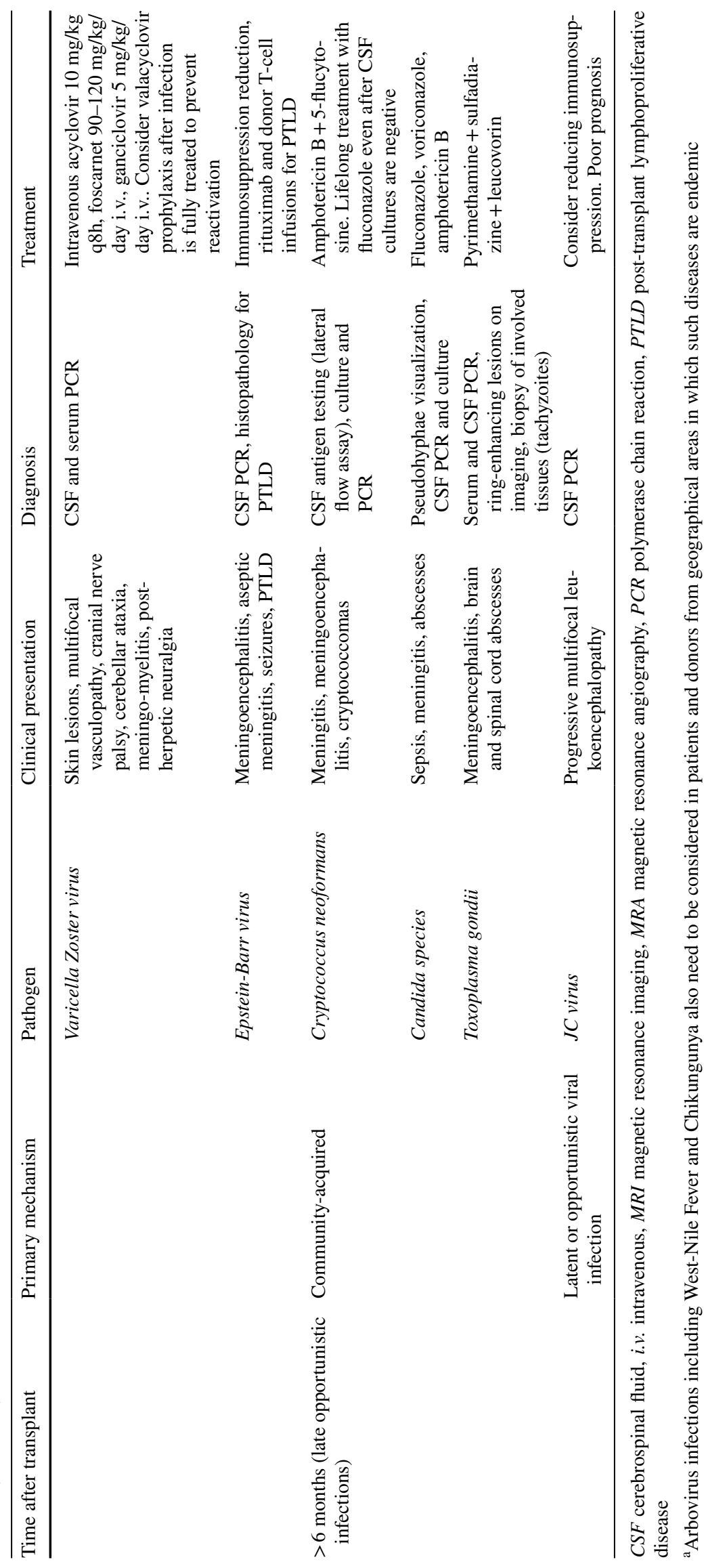


in patients older than 65 years, however premedication with methylprednisolone, paracetamol and antihistamines may reduce the frequency and severity of side effects.

Treatment of CNS infections includes empiric antimicrobial therapy based on ceftriaxone, ampicillin and acyclovir until the causal pathogen has been identified. A central issue with the use of antiviral drugs in kidney transplant recipients is represented by their potential nephrotoxicity. Cidofovir and, to a lesser extent, acyclovir may cause direct tubular toxicity and can also induce crystal deposition in the kidney that may result in renal failure. Hydration, slow intravenous administration and dose reduction in case of reduced glomerular filtration rate are important preventive measures. Azole antifungals are significantly metabolized by CYP3A4 and can therefore inhibit the catabolism of CsA, TAC and mTOR inhibitors, thus extreme caution is advised when using these agents in kidney transplant recipients.

Immunosuppressive drugs are usually tapered in the acute phase, unless the patient's history suggests a disproportionally high risk of graft rejection. Indeed, infections pose a challenge in balancing antimicrobial therapy and inflammatory response in transplant recipients. A reduction of the immunosuppressive regimen to contain the infection might also cause immune reconstitution inflammatory syndrome [62]. This condition represents a diagnosis of exclusion and needs to be considered when patients present novel or worsening neurological clinical/radiological features associated with negative cultures.

\section{Psychiatric disorders}

Glucocorticoids are extensively employed as maintenance immunosuppression and for the treatment of acute rejection. Patients treated with glucocorticoids can suffer from different behavioral disorders, ranging from minor mood alterations and confusion to severe psychotic reactions [63]. Dose reduction may be sufficient to reverse or improve symptoms, even though antidepressant or neuroleptic treatment is required in selected cases. In case of psychosis or mania, prophylaxis with lithium and olanzapine may be considered. The risk of these side effects is increased by older age, previous history of psychiatric disorders, steroid dose, and treatment duration. Behavioral disorders can also complicate therapy with CNIs and mTOR inhibitors. The BENEFIT and BENEFIT-EXT trials compared patients undergoing maintenance immunosuppression with belatacept or CsA and observed that patients in the latter group displayed higher frequency of emotion-related side effects, such as depression, anxiety, or restlessness [64].

\section{Chronic clinical presentations}

\section{Malignancy}

Transplant recipients have a well-known increased risk of malignancies compared to the general population, which is a direct consequence of reduced immuno-surveillance and increased susceptibility to infections with oncogenic viruses. The risk of developing systemic lymphoma in the first year after renal transplantation has been estimated to be 20 times higher than in the general population [65]. Almost 30\% of all post-transplant lymphoproliferative disorders (PTLD) affect the CNS [66] and the most frequent malignant form is represented by large diffuse B-cell lymphoma, which accounts for only $2 \%$ of CNS malignancies in the general population. Many PTLD cases result from prior EBV infection, even though CSF and serum analyses might be negative for EBV-DNA and the specific pathogenic mechanism remains unclear [67]. EBV-negative patients are at high risk of cerebral lymphoma if the donor is a carrier of EBV. In such cases, immunosuppression should be maintained as low as possible and the use of belatacept should be avoided.

Clinical manifestations are variable depending on site and extension of the lesions with peripheral facial nerve palsy representing an early sign of PTLD with meningeal involvement. Definitive diagnosis usually requires a brain biopsy. Careful reduction of the immunosuppressive regimen based on the patient's history of rejection is mandatory. Treatment options include rituximab, chemotherapy and surgery if the disease is localized.

\section{Optic neuropathy}

Optic neuropathy is a rare but well-recognized side effect of tacrolimus administration, which may occur from months to years after treatment initiation [68]. Patients may experience visual acuity impairment that can evolve into progressive severe visual loss, resulting in complete blindness. This complication usually affects both optic nerves, but unilateral symptoms have also been described, especially at disease onset [69]. Ophthalmic examination can show variable findings depending on disease stage, which may range from unremarkable to optic disc edema or pallor [69]. Brain and orbital MRI might reveal optic nerve inflammation in the form of contrast enhancement and $\mathrm{T} 2$ hyperintensity. The common clinical practice is to switch tacrolimus with another immunosuppressive agent, although unfortunately, visual impairment may be irreversible in many cases [68]. 


\section{Peripheral nervous system}

\section{Acute clinical presentations}

\section{Guillain-Barré syndrome}

Guillain-Barré syndrome (GBS) is the most common acute inflammatory polyradiculoneuropathy, affecting 0.8-1.9 patients per 100,000 per year [70]. The typical clinical evolution includes a first phase of ascending, mostly symmetrical, limb weakness and areflexia, progressing to its peak in 2-4 weeks, followed by a plateau phase that may last several months, and a subsequent recovery phase, in some cases incomplete with residual disability.

CMV is the most common viral cause of GBS, and it has been associated with most cases occurring in solid organ recipients, supporting the hypothesis that in these patients viral infections can act as relevant triggers for acute nerve inflammation [71]. GBS has been observed in numerous recipients of bone marrow transplant (BMT), particularly in those undergoing allogeneic BMT [72], but it is rarely seen after solid organ transplantation [73], although these patients are more susceptible to opportunistic infections as a result of immune suppression.

At present, 19 cases of GBS occurring in kidney recipients have been described in the literature [74, 75]. A systematic review already included the first 17 described cases, identifying an infectious trigger in 15 of them (88\%), the most common being CMV infection or re-activation in seronegative patients receiving a kidney from a seropositive donor (80\%); immunosuppressive treatment alone was possibly implicated in only two cases, although at least 13 patients (76\%) were receiving CNIs [74]. Patients treated with standard GBS therapy based either on immunoglobulins $(0.4 \mathrm{~g} / \mathrm{kg} /$ day for 5 days) or plasma exchange (three cycles) achieved full neurological recovery. Immunosuppressive (TAC and/or MMF) dose reduction or suspension was reported in only three patients.

A recent single-center retrospective analysis identified 2 patients developing GBS in a cohort of 143 alemtuzumab treated kidney recipients, $92 \%$ of whom were receiving TAC-based immunosuppressive therapy (including the 2 GBS cases), within a mean interval of 6 months from alemtuzumab infusion. No recent infection was identified in either case [75]. However, the study found no causal link between monoclonal antibody therapy and the development of GBS, and therefore the role of possible reactivation of $\mathrm{CMV}$, at least in one of the two patients who was seropositive at the time of transplantation, cannot be excluded as a predisposing factor for GBS.

Taken together, these data confirm that GBS is rare in renal transplant recipients, suggesting that immunosuppression gives a certain degree of protection. This hypothesis is supported by the immunomodulatory effects of MMF, which could mitigate the immune mechanisms underlying GBS development, and the effective use of CsA in the treatment of inflammatory neuropathies [76]. However, more data are needed to understand the correct management of immunomodulating treatment in these patients.

An infectious etiology, particularly CMV re-activation, is postulated or strongly suspected in most of the cases described, which represents a higher percentage than that reported for the general adult population. Moreover, all patients receiving at least one approved immunotherapy for GBS achieved full recovery, except for one CMV-associated subject who did not fully recover lower limb strength.

Therefore, the combination of antiviral medications with standard GBS therapy seems to determine the best outcome and should be offered to all patients in whom a viral etiology cannot be excluded. More information is needed to understand which is the best therapeutic approach.

\section{Myasthenia gravis}

Myasthenia gravis (MG) is the most frequent disorder of the neuromuscular junction. It is associated with antibodies directed against the postsynaptic membrane at the muscle endplate, manifesting as fatigue and muscle weakness. An abrupt worsening of symptoms, called myasthenic crisis, may lead the patient to require respiratory support. It can occur spontaneously as part of the natural history of the disease itself, but it can also be triggered by a number of factors; infections, pregnancy, childbirth, surgery and different drugs.

To date, the literature reports only anecdotal cases of myasthenic crises in patients treated with CNIs following renal transplantation $[77,78]$. However, it was not possible to establish a direct correlation with immunosuppressive anti-rejection therapy in any of these cases due to simultaneous confounding factors (i.e. surgical procedures, infection, antibiotic therapy). Moreover, glucocorticoids, azathioprine and CNIs are listed among the conventional immunosuppressants in the treatment of MG [79]. In the most recently described case, muscle weakness began one year after the transplant and the authors also excluded any correlation between myasthenic crisis and alemtuzumab, which was used as induction therapy 1 year before the onset of neuromuscular symptoms [78].

A direct association between MG and renal transplant is therefore unlikely, but patients with an established MG diagnosis who undergo kidney transplantation must be tightly monitored. It is crucial for physicians to be aware that $\mathrm{MG}$ symptoms are likely to deteriorate suddenly during the perioperative period. Although there are few supporting data 
in the literature, conventional myasthenic crisis treatments (pyridostigmine, i.v.immunoglobulins, plasma exchange) also seem to be effective in these patients.

\section{Chronic clinical presentations}

\section{Tremors}

Tremors affect approximately one-third of renal transplant recipients, with variable degrees of symptom severity ranging from mild to highly incapacitating [80]. CNIs are mostly responsible for this disorder, possibly due to their serotonindepletion effect on neurons [81]. Affected patients usually develop fine resting and action tremors involving the upper extremities, which may significantly impact on daily activities. Although tremors may develop following exposure to any CNI, TAC has been more frequently associated with this disorder compared to CsA [82-84].

CNI-induced tremors are generally regarded as a dosedependent effect due to over-exposure. Monitoring TAC and CsA trough levels is frequently used as a method to assess CNI exposure, but blood levels do not always correlate with intracellular concentrations and pharmacologic effect [85]. CNI-induced tremors may also develop in patients with TAC/CsA blood levels in the "correct" therapeutic range.

Dose reduction of CNIs may lead to significant improvement in symptoms, and some patients may also respond to beta-blockers. Extended-release formulations of tacrolimus may provide some benefit over conventional forms, but randomized controlled trials in this context are still lacking [86, 87].

\section{Hearing complications}

Hearing loss, tinnitus or otalgia may develop in CNI-treated patients. A questionnaire administered to 521 liver transplant recipients under treatment with TAC reported that $14 \%$ developed hearing loss [88]. Hearing loss may also occur in pediatric renal transplant recipients treated with high doses of TAC [89] or CsA [90]. It has been suggested that deafness might be initiated by a sudden spike in the TAC serum level, which is later worsened by its cumulative toxic effect [91], accordingly, dose correction may lead to hearing recovery.

\section{Toxic neuropathies}

Peripheral toxic neuropathy is the most frequent neurological adverse event in renal transplant patients, with an overall prevalence of more than 2\% [54]. Among drugs used for immunosuppression in kidney transplant patients, CNIs are responsible for most of the toxic effects on the peripheral nerve. A painful sensory peripheral neuropathy is also very frequent in patients treated with bortezomib, a proteasome inhibitor used for antibody-mediated rejection.

Patients receiving CNI therapy show nerve function abnormalities, quantified through nerve excitability measures, consistent with nerve membrane depolarization. In 2007, the first two kidney recipients who developed sensorimotor neuropathy while on therapy with TAC were reported, showing different electrophysiological findings (either predominantly demyelinating or axonal) of neuropathic damage [92]. One of these patients showed clinical, CSF and neurophysiologic findings suggestive of relapsing chronic inflammatory demyelinating polyneuropathy (CIDP), which was responsive to repeated i.v. immunoglobulin treatments. This case has many similarities to that of a kidney transplant recipient who developed life-threatening sensory-motor peripheral neuropathy 10 years after the graft, suggesting a diagnosis of CIDP [93]. The authors postulated a causal role of TAC, hinted at by the temporal relationship, the long-term response after cessation of treatment and the exclusion of other causes, and they theorized a TAC-induced trigger acting on an inflammatory substrate given the quick response to $\mathrm{v}$ i.v. immunoglobulin treatment. TAC was switched to sirolimus, which was well tolerated. A prospective study on solid organ recipients reported three more patients developing CIDP within a time interval between 8 and 36 months while on CsA 400-600 mg/day [94]. All these patients received a final diagnosis of typical definite CIDP. They continued to take CsA and showed brilliant response to i.v. immunoglobulin treatment and a monophasic disease course with no relapses observed within a follow-up period of at least 4 years.

Several factors may contribute to the occurrence of CIDP in renal transplant patients. CNIs still play an unclear role since they have been described as provoking demyelinating neuropathy but also as having positive effects on CIDP [95]. Patients receiving CNIs should be carefully monitored for neuropathic symptoms, and CIDP should be suspected in all patients with compatible clinical and neurophysiological characteristics, after excluding other etiologies. Reducing CNI dose or switching to alternative drugs such as mTOR inhibitors should be considered in such patients.

Bortezomib-induced peripheral neuropathy is a wellknown adverse event of the drug. A prospective study evaluated the toxicity profile of bortezomib in 51 kidney recipients undergoing antibody-mediated rejection [96]. The study revealed that $26.4 \%$ of patients showed typical sensory new onset or worsening peripheral neuropathy of mild degree. Patients exhibited improvement of symptoms at the end of treatment, with complete resolution of new onset peripheral neuropathy being observed in $91.7 \%$ of patients. Since bortezomib toxicity on peripheral nerves seems to be mild and reversible, patients should undergo periodic clinical assessments, with appropriate dose changes until 
suspension. Tricyclic antidepressants, selective serotoninnorepinephrine reuptake inhibitors, pregabalin and gabapentin should be used in the management of symptoms [97].

Finally, toxic neuropathy should be differentiated from CNI-induced pain syndrome, a rare but severe side effect. The disease should be suspected in patients complaining of movement-related, lower limb symmetric deep aching pain, especially soon after transplantation, and the diagnosis is confirmed by bone scintigraphy and magnetic resonance imaging. However, this syndrome is uncommon among kidney transplant patients, with a prevalence of $0.8-5.8 \%$ [98, 99]. Pregabalin may be administered as the drug of choice.

\section{Autonomic neuropathy}

The involvement of the autonomous system is common in patients with chronic kidney disease, especially due to the high prevalence of diabetes in this population. Autonomic neuropathies in these patients are frequently axonal, hence longer nerves (e.g. the vagus nerve) are affected earlier. Typical manifestations range from blood pressure disorders (orthostatic hypotension, increased peripheral vascular resistance and reductions in day-to-night blood pressure variations) due to impaired baroreceptor function, gastrointestinal symptoms (gastroparesis and alternating constipation/diarrhea) and genitourinary disorders (incontinence, erectile dysfunction). Some improvement in cardiovascular autonomic function has been reported in dialysis patients after renal transplantation [100], but other studies have described the persistence of autonomic dysfunction in renal transplant recipients [101, 102]. These effects may be in part due to the use of immunosuppressive drugs, which may affect autonomic function [103]. Symptomatic treatment may provide some relief, but no study to date has explored the effect of different immunosuppressive regimens on autonomic neuropathy.

\section{Myopathy}

Steroid-induced myopathy can arise after a variable period of time and involves proximal muscle weakness with atrophy [104]. These forms preferentially affect the lower extremities and patients sometimes experience myalgia or cramps. The diagnosis is clinical, muscular enzymes are usually not elevated and treatment is focused on steroid tapering.

\section{Prevention and management}

Many neurological complications in transplant patients are related to comorbidity, hence early treatment of hypertension, diabetes mellitus and dyslipidemia is of paramount importance. Nevertheless, the best measure to prevent complications in an immunocompromised patient is to minimize immunosuppressive therapy. However, since this approach can expose transplant recipients to rejection and graft failure, knowledge of the immune status of a patient would be of great importance to decide the intensity of the anti-rejection therapy.

Several studies have been conducted in the search for tests able to assess the immunological status of transplant recipients, with the ultimate goal of predicting the risk of both rejection and of complications due to over-immunosuppression [105]. Monitoring donor-specific anti-HLA antibodies can be useful to predict the risk of antibody-mediated rejection and poor renal outcomes [106], but this method cannot provide quantifiable information regarding the degree of immunosuppression. Assays that test recipient T-cell reactivity against donor cells (mixed lymphocyte reaction and cell-mediated lympholysis) have been advocated as a possible tool to gauge immunosuppression intensity [107], but these techniques are time-consuming and difficult to standardize. Enzyme-linked immunosorbent spot (ELISPOT) assays have been used to assess cytokine production from donor-specific T-cells, to investigate viral infection susceptibility, and to attempt withdrawal of immunosuppressive medications in tolerant patients. However, most studies conducted so far have been retrospective, and conflicting results have been reported [108], thus further studies are needed to validate the role of this assay as a marker of the immune status of transplant recipients [105].

Two additional assays were developed to characterize immunosuppression intensity, based either on the quantification of adenosine triphosphate released by CD4+ T cells [109], or on the measurement of IFN $\gamma$ levels in blood samples after exogenous stimulation of both the innate and adaptive immune systems [110]. Despite initial enthusiasm, none of these assays have been translated to clinical practice.

More recently, monitoring replication of torque teno virus (TTV), a non-enveloped single-strand DNA virus that is part of the human virome, has been proposed as an additional tool to assess immune function in renal transplant recipients. In a prospective observational study, low TTV loads during the first year post-transplant were associated with rejection, while high levels predicted infectious complications [111]. An optimal TTV range was defined, but further studies will be required to evaluate whether TTV-guided immunosuppression could improve short- and long-term outcomes in these patients.

Since standard methods to assess the intensity of immunosuppression are still lacking, physicians should try to adjust immunosuppressive therapy on the basis of features such as age, clinical history, and comorbidities. Elderly patients experience a decline in natural and adaptive immunity [112], while the activity of cytochrome P450 enzymes is reduced with advanced age [113]. Since these enzymes regulate the catabolism of CNIs, mTOR inhibitors and glucocorticoids, accumulation of these drugs can occur in 
elderly individuals. In addition, hypertension, diabetes, and cardiovascular and cerebrovascular disease are common in older candidates to kidney transplantation. Therefore, in older individuals, immunosuppressive therapy should be tailored to a less vigorous approach by avoiding or withdrawing glucocorticoids after the induction phase [114].

\section{Conclusions}

Kidney transplant recipients are at risk of various neurological complications, mainly due to immunosuppressive drugs, and in general to their pre- and post-transplant comorbidities. These side effects can range from tremor, dizziness and paresthesia to more complex and life-threatening clinical conditions. Prevention, early diagnosis and appropriate management of these complications are critical to prevent irreversible lesions. In the past, neurological adverse events mainly occurred within a few weeks from transplant and were frequently related to opportunistic infections. In more recent years, since CNIs and other effective immunosuppressive drugs have been made available, there have been tremendous advances in the field of organ transplantation with considerable improvement in the short- and long-term survival of the patient and of the kidney allograft. Since the main focus of this review is to provide a working summary of the more common and potentially severe immunosuppression-related neurological complications in a framework based on urgency and anatomic site, our work cannot be regarded as exhaustively comprehensive, and readers interested in any of the covered topics are encouraged to pursue additional information through the cited references. More data from basic and clinical studies are needed to address the knowledge gaps in both the pathogenesis and treatment of many of these complications, and clinical decisions should take into account inter-patient variability. For these reasons, we also encourage close collaboration between nephrologists and neurologists, not only to allow correct and rapid identification of these neurological disorders, but also to provide the best therapeutic strategy in managing the delicate balance between immunosuppression and serious adverse effects.

Funding Open Access funding provided by Università degli Studi di Milano.

\section{Compliance with ethical standards}

Conflict of interest The authors declare that they have no conflict of interest.

Ethical approval This article does not contain any studies with human participants or animals performed by any of the authors.
Informed consent For this type of study formal consent is not required.

Open Access This article is licensed under a Creative Commons Attribution 4.0 International License, which permits use, sharing, adaptation, distribution and reproduction in any medium or format, as long as you give appropriate credit to the original author(s) and the source, provide a link to the Creative Commons licence, and indicate if changes were made. The images or other third party material in this article are included in the article's Creative Commons licence, unless indicated otherwise in a credit line to the material. If material is not included in the article's Creative Commons licence and your intended use is not permitted by statutory regulation or exceeds the permitted use, you will need to obtain permission directly from the copyright holder. To view a copy of this licence, visit http://creativecommons.org/licenses/by/4.0/.

\section{References}

1. Rizzo MA, Frediani F, Granata A et al (2012) Neurological complications of hemodialysis: state of the art. J Nephrol 25:170 182. https://doi.org/10.5301/jn.5000087

2. Ponticelli C, Glassock RJ (2019) Prevention of complications from use of conventional immunosuppressants: a critical review. J Nephrol 32:851-870. https://doi.org/10.1007/s40620-01900602-5

3. Dohgu S, Yamauchi A, Nakagawa S et al (2004) Nitric oxide mediates cyclosporine-induced impairment of the blood-brain barrier in cocultures of mouse brain endothelial cells and rat astrocytes. Eur J Pharmacol 505:51-59. https://doi.org/10.1016/j. ejphar.2004.10.027

4. Kochi S, Takanaga H, Matsuo H et al (2000) Induction of apoptosis in mouse brain capillary endothelial cells by cyclosporin a and tacrolimus. Life Sci 66:2255-2260. https://doi.org/10.1016/ S0024-3205(00)00554-3

5. Stoltenburg-Didinger G, Boegner F (1992) Glia toxicity in dissociation cell cultures induced by cyclosporine. Neurotoxicology 13:179-184

6. McDonald JW, Goldberg MP, Gwag BJ et al (1996) Cyclosporine induces neuronal apoptosis and selective oligodendrocyte death in cortical cultures. Ann Neurol 40:750-758. https://doi. org/10.1002/ana.410400511

7. Jin KB, Choi HJ, Kim HT et al (2008) The production of reactive oxygen species in tacrolimus-treated glial cells. Transplant Proc 40:2680-2681. https://doi.org/10.1016/j.transproce ed.2008.08.033

8. Sander M, Lyson T, Thomas GD, Victor RG (1996) Sympathetic neural mechanisms of cyclosporine-induced hypertension. Am J Hypertens 9:121S-138S. https://doi.org/10.1016/08957061(96)00288-9

9. Gold BG (1997) FK506 and the role of immunophilins in nerve regeneration. Mol Neurobiol 15:285-306. https://doi. org/10.1007/BF02740664

10. Arnold R, Pussell BA, Pianta TJ et al (2013) Association between calcineurin inhibitor treatment and peripheral nerve dysfunction in renal transplant recipients. Am J Transplant 13:2426-2432. https://doi.org/10.1111/ajt.12324

11. Hoorn EJ, Walsh SB, McCormick JA et al (2012) Pathogenesis of calcineurin inhibitor-induced hypertension. J Nephrol 25:269275. https://doi.org/10.5301/jn.5000174

12. Uchino H, Minamikawa-Tachino R, Kristián T et al (2002) Differential neuroprotection by cyclosporin A and FK506 following ischemia corresponds with differing abilities to inhibit 
calcineurin and the mitochondrial permeability transition. Neurobiol Dis 10:219-233. https://doi.org/10.1006/nbdi.2002.0514

13. Bochelen D, Rudin M, Sauter A (1999) Calcineurin inhibitors FK506 and SDZ ASM 981 alleviate the outcome of focal cerebral ischemic/reperfusion injury. J Pharmacol Exp Ther 288:653-659

14. Nito C, Ueda M, Inaba T et al (2011) FK506 ameliorates oxidative damage and protects rat brain following transient focal cerebral ischemia. Neurol Res 33:881-889. https://doi. org/10.1179/1743132811Y.0000000019

15. Partoazar A, Nasoohi S, Rezayat SM et al (2017) Nanoliposome containing cyclosporine A reduced neuroinflammation responses and improved neurological activities in cerebral ischemia/reperfusion in rat. Fundam Clin Pharmacol 31:185-193. https://doi. org/10.1111/fcp. 12244

16. Furuichi Y, Katsuta K, Maeda M et al (2003) Neuroprotective action of tacrolimus (FK506) in focal and global cerebral ischemia in rodents: dose dependency, therapeutic time window and long-term efficacy. Brain Res 965:137-145. https://doi. org/10.1016/s0006-8993(02)04151-3

17. Malouitre S, Dube H, Selwood D, Crompton M (2009) Mitochondrial targeting of cyclosporin A enables selective inhibition of cyclophilin-D and enhanced cytoprotection after glucose and oxygen deprivation. Biochem J 425:137-148. https://doi. org/10.1042/BJ20090332

18. Panettieri RA, Schaafsma D, Amrani Y et al (2019) Non-genomic effects of glucocorticoids: an updated view. Trends Pharmacol Sci 40:38-49. https://doi.org/10.1016/j.tips.2018.11.002

19. Joëls M (2018) Corticosteroids and the brain. J Endocrinol 238:R121-R130. https://doi.org/10.1530/JOE-18-0226

20. Moisiadis VG, Matthews SG (2014) Glucocorticoids and fetal programming part 1: Outcomes. Nat Rev Endocrinol 10:391402. https://doi.org/10.1038/nrendo.2014.73

21. Sousa N, Almeida OFX (2012) Disconnection and reconnection: the morphological basis of (mal)adaptation to stress. Trends Neurosci 35:742-751. https://doi.org/10.1016/j.tins.2012.08.006

22. Bockaert J, Marin P (2015) mTOR in brain physiology and pathologies. Physiol Rev 95:1157-1187. https://doi.org/10.1152/ physrev.00038.2014

23. Ramanathan A, Schreiber SL (2009) Direct control of mitochondrial function by mTOR. Proc Natl Acad Sci USA 106:2222922232. https://doi.org/10.1073/pnas.0912074106

24. Wang Y, Barbaro MF, Baraban SC (2006) A role for the mTOR pathway in surface expression of AMPA receptors. Neurosci Lett 401:35-39. https://doi.org/10.1016/j.neulet.2006.03.011

25. Jin M-M, Wang F, Qi D et al (2018) A critical role of autophagy in regulating microglia polarization in neurodegeneration. Front Aging Neurosci 10:378. https://doi.org/10.3389/fnagi .2018 .00378

26. Pignataro G, Capone D, Polichetti G et al (2011) Neuroprotective, immunosuppressant and antineoplastic properties of mTOR inhibitors: current and emerging therapeutic options. Curr Opin Pharmacol 11:378-394. https://doi.org/10.1016/j. coph.2011.05.003

27. Klawitter J, Gottschalk S, Hainz C et al (2010) Immunosuppressant neurotoxicity in rat brain models: oxidative stress and cellular metabolism. Chem Res Toxicol 23:608-619. https://doi. org/10.1021/tx900351q

28. Carson KR, Evens AM, Richey EA et al (2009) Progressive multifocal leukoencephalopathy after rituximab therapy in HIV-negative patients: a report of 57 cases from the research on adverse drug events and reports project. Blood 113:4834-4840. https:// doi.org/10.1182/blood-2008-10-186999

29. Kapoor T, Mahadeshwar P, Hui-Yuen J et al (2020) Prevalence of progressive multifocal leukoencephalopathy (PML) in adults and children with systemic lupus erythematosus. Lupus Sci Med. https://doi.org/10.1136/lupus-2020-000388

30. Toyoda M, Thomas D, Ahn G et al (2015) JC polyomavirus viremia and progressive multifocal leukoencephalopathy in human leukocyte antigen-sensitized kidney transplant recipients desensitized with intravenous immunoglobulin and rituximab. Transpl Infect Dis 17:838-847. https://doi.org/10.1111/tid.12465

31. Avivi I, Chakrabarti S, Kottaridis P et al (2004) Neurological complications following alemtuzumab-based reduced-intensity allogeneic transplantation. Bone Marrow Transplant 34:137-142. https://doi.org/10.1038/sj.bmt.1704538

32. Vincenti F, Blancho G, Durrbach A et al (2010) Five-year safety and efficacy of belatacept in renal transplantation. J Am Soc Nephrol 21:1587-1596. https://doi.org/10.1681/ASN.20091 11109

33. Estol CJ, Lopez O, Brenner RP, Martinez AJ (1989) Seizures after liver transplantation: a clinicopathologic study. Neurology 39:1297-1301. https://doi.org/10.1212/wnl.39.10.1297

34. Sevmis S, Karakayali H, Emiroglu R et al (2007) Tacrolimusrelated seizure in the early postoperative period after liver transplantation. Transplant Proc 39:1211-1213. https://doi. org/10.1016/j.transproceed.2007.02.049

35. Yardimci N, Colak T, Sevmis S et al (2008) Neurologic complications after renal transplant. Exp Clin Transplant 6:224-228

36. Odeh M, Lavy A, Stermer E (2003) Hydrocortisone-induced convulsions. J Toxicol Clin Toxicol 41:995-997. https://doi. org/10.1081/clt-120026524

37. Ponticelli C, Campise MR (2005) Neurological complications in kidney transplant recipients. J Nephrol 18:521-528

38. Nankivell BJ, Lau SG, Chapman JR et al (2000) Progression of macrovascular disease after transplantation. Transplantation 69:574-581. https://doi.org/10.1097/00007890-20000 2270-00019

39. Shoskes A, Wilson R (2019) Neurologic complications of kidney transplantation. Transl Androl Urol 8:164-172. https://doi. org/10.21037/tau.2018.08.11

40. Kazory A, Ducloux D (2004) Acquired hypercoagulable state in renal transplant recipients. Thromb Haemost 91:646-654. https ://doi.org/10.1160/TH03-09-0568

41. Satterthwaite R, Aswad S, Sunga V et al (1998) Incidence of new-onset hypercholesterolemia in renal transplant patients treated with FK506 or cyclosporine. Transplantation 65:446449. https://doi.org/10.1097/00007890-199802150-00030

42. Liu J, Liu D, Li J et al (2017) Efficacy and safety of everolimus for maintenance immunosuppression of kidney transplantation: a meta-analysis of randomized controlled trials. PLoS ONE 12:e170246. https://doi.org/10.1371/journal.pone.0170246

43. Wijdicks EF, Torres VE, Schievink WI, Sterioff S (1999) Cerebral hemorrhage in recipients of renal transplantation. Mayo Clin Proc 74:1111-1112. https://doi.org/10.4065/74.11.1111

44. Willicombe M, Kumar N, Goodall D et al (2015) Incidence, risk factors, and outcomes of stroke post-transplantation in patients receiving a steroid sparing immunosuppression protocol. Clin Transplant 29:18-25. https://doi.org/10.1111/ctr.12476

45. Fugate JE, Rabinstein AA (2015) Posterior reversible encephalopathy syndrome: clinical and radiological manifestations, pathophysiology, and outstanding questions. Lancet Neurol 14:914-925. https://doi.org/10.1016/S1474-4422(15)00111-8

46. Bartynski WS, Tan HP, Boardman JF et al (2008) Posterior reversible encephalopathy syndrome after solid organ transplantation. AJNR Am J Neuroradiol 29:924-930. https://doi. org/10.3174/ajnr.A0960

47. Roth C, Ferbert A (2011) The posterior reversible encephalopathy syndrome: what's certain, what's new? Pract Neurol 11:136144. https://doi.org/10.1136/practneurol-2011-000010 
48. Johannessen SI, Landmark CJ (2010) Antiepileptic drug interactions-principles and clinical implications. Curr Neuropharmacol 8:254-267. https://doi.org/10.2174/157015910792246254

49. Shepard PW, St Louis EK (2012) Seizure treatment in transplant patients. Curr Treat Options Neurol 14:332-347. https:// doi.org/10.1007/s11940-012-0180-y

50. Chtioui H, Zimmermann A, Dufour J-F (2005) Unusual evolution of posterior reversible encephalopathy syndrome (PRES) one year after liver transplantation. Liver Transpl 11:588-590. https ://doi.org/10.1002/lt.20425

51. Wu Q, Marescaux C, Wolff V et al (2010) Tacrolimus-associated posterior reversible encephalopathy syndrome after solid organ transplantation. Eur Neurol 64:169-177. https://doi. org/10.1159/000319032

52. Berger JR, Neltner J, Smith C, Cambi F (2014) Posterior reversible encephalopathy syndrome masquerading as progressive multifocal leukoencephalopathy in rituximab treated neuromyelitis optica. Mult Scler Relat Disord 3:728-731. https://doi. org/10.1016/j.msard.2014.08.004

53. Touhami S, Arzouk N, Darugar A et al (2014) Everolimusinduced posterior reversible encephalopathy syndrome and bilateral optic neuropathy after kidney transplantation. Transplantation 98:e102-104. https://doi.org/10.1097/TP.000000000000055 1

54. Mohammadi MH, Salarzaei M, Parooie F (2019) Neurological complications after renal transplantation: a systematic review and meta-analysis. Ther Apher Dial 23:518-528. https://doi. org/10.1111/1744-9987.12838

55. Navarro D, San-Juan R, Manuel O et al (2017) Cytomegalovirus infection management in solid organ transplant recipients across European centers in the time of molecular diagnostics: an ESGICH survey. Transpl Infect Dis. https://doi.org/10.1111/ tid. 12773

56. Anesi JA, Baddley JW (2016) Approach to the solid organ transplant patient with suspected fungal infection. Infect Dis Clin N Am 30:277-296. https://doi.org/10.1016/j.idc.2015.10.001

57. Major EO, Yousry TA, Clifford DB (2018) Pathogenesis of progressive multifocal leukoencephalopathy and risks associated with treatments for multiple sclerosis: a decade of lessons learned. Lancet Neurol 17:467-480. https://doi.org/10.1016/ S1474-4422(18)30040-1

58. Medrano C, Vergez F, Mengelle C et al (2019) Effectiveness of immune checkpoint inhibitors in transplant recipients with progressive multifocal leukoencephalopathy. Emerging Infect Dis 25:2145-2147. https://doi.org/10.3201/eid2511.190705

59. Ohara H, Kataoka H, Nakamichi K et al (2014) Favorable outcome after withdrawal of immunosuppressant therapy in progressive multifocal leukoencephalopathy after renal transplantation: case report and literature review. J Neurol Sci 341:144-146. https://doi.org/10.1016/j.jns.2014.03.048

60. Muftuoglu M, Olson A, Marin D et al (2018) Allogeneic BK virus-specific $\mathrm{T}$ cells for progressive multifocal leukoencephalopathy. N Engl J Med 379:1443-1451. https://doi. org/10.1056/NEJMoa1801540

61. Bugelski PJ, Achuthanandam R, Capocasale RJ et al (2009) Monoclonal antibody-induced cytokine-release syndrome. Expert Rev Clin Immunol 5:499-521. https://doi.org/10.1586/ eci.09.31

62. Jackowiak E, Shah N, Chen $\mathrm{H}$ et al (2019) A case of immune reconstitution syndrome complicating progressive multifocal leukoencephalopathy after kidney transplant: clinical, pathological, and radiographic features. Transpl Infect Dis 21:e13162. https:// doi.org/10.1111/tid.13162

63. Perantie DC, Brown ES (2002) Corticosteroids, immune suppression, and psychosis. Curr Psychiatry Rep 4:171-176. https://doi. org/10.1007/s11920-002-0023-8
64. Dobbels F, Wong S, Min Y et al (2014) Beneficial effect of belatacept on health-related quality of life and perceived side effects: results from the BENEFIT and BENEFIT-EXT trials. Transplantation 98:960-968. https://doi.org/10.1097/TP.00000 00000000159

65. Jagadeesh D, Woda BA, Draper J, Evens AM (2012) Post transplant lymphoproliferative disorders: risk, classification, and therapeutic recommendations. Curr Treat Options Oncol 13:122-136. https://doi.org/10.1007/s11864-011-0177-x

66. Piotrowski PC, Lutkowska A, Tsibulski A et al (2017) Neurologic complications in kidney transplant recipients. Folia Neuropathol 55:86-109. https://doi.org/10.5114/fn.2017.68577

67. Morscio J, Tousseyn T (2016) Recent insights in the pathogenesis of post-transplantation lymphoproliferative disorders. World $\mathrm{J}$ Transplant 6:505-516. https://doi.org/10.5500/wjt.v6.i3.505

68. Alnahdi MA, Al Malik YM (2019) Delayed tacrolimus-induced optic neuropathy. Neurosciences (Riyadh) 24:324-326. https:// doi.org/10.17712/nsj.2019.4.20190022

69. Rasool N, Boudreault K, Lessell S et al (2018) Tacrolimus optic neuropathy. J Neuroophthalmol 38:160-166. https://doi. org/10.1097/WNO.0000000000000635

70. Sejvar JJ, Baughman AL, Wise M, Morgan OW (2011) Population incidence of Guillain-Barré syndrome: a systematic review and meta-analysis. Neuroepidemiology 36:123-133. https://doi. org/10.1159/000324710

71. Myers SE, Williams SF (1994) Guillain-Barré syndrome after autologous bone marrow transplantation for breast cancer: report of two cases. Bone Marrow Transplant 13:341-344

72. Yoshida T, Ueki Y, Suzuki T et al (2016) Guillain-Barré syndrome after allogeneic bone marrow transplantation: case report and literature review. eNeurologicalSci 4:52-55. https://doi. org/10.1016/j.ensci.2016.08.001

73. El-Sabrout RA, Radovancevic B, Ankoma-Sey V, Van Buren CT (2001) Guillain-Barré syndrome after solid organ transplantation. Transplantation 71:1311-1316. https://doi.org/10.1097/00007 890-200105150-00023

74. Ostman C, Chacko B (2019) Guillain-Barré syndrome post renal transplant: a systematic review. Transpl Infect Dis 21:e13021. https://doi.org/10.1111/tid.13021

75. van der Zwan M, Hesselink DA, Brusse E et al (2020) Guillain-Barré syndrome and chronic inflammatory demyelinating polyradiculoneuropathy after alemtuzumab therapy in kidney transplant recipients. Neurol Neuroimmunol Neuroinflamm. https://doi.org/10.1212/NXI.0000000000000721

76. Barnett MH, Pollard JD, Davies L, McLeod JG (1998) Cyclosporin A in resistant chronic inflammatory demyelinating polyradiculoneuropathy. Muscle Nerve 21:454-460. https ://doi.org/10.1002/(sici)1097-4598(199804)21:4\%3c454 ::aid-mus3\%3e3.0.co;2-8

77. Nieto-Ríos JF, Zuluaga Quintero M, Moreno Gómez L et al (2016) Myasthenia gravis after kidney transplantation. Nefrologia 36:716-718. https://doi.org/10.1016/j.nefro.2016.05.006

78. O'Reilly S, Walshe E, Breathnach A et al (1992) Myasthenia gravis associated with cyclosporin treatment. Nephrol Dial Transplant 7:455

79. Sanders DB, Wolfe GI, Benatar M et al (2016) International consensus guidance for management of myasthenia gravis: executive summary. Neurology 87:419-425. https://doi. org/10.1212/WNL.0000000000002790

80. Bechstein WO (2000) Neurotoxicity of calcineurin inhibitors: impact and clinical management. Transpl Int 13:313-326. https ://doi.org/10.1007/s001470050708

81. Senzolo M, Marco S, Ferronato C et al (2009) Neurologic complications after solid organ transplantation. Transpl Int 22:269-278. https://doi.org/10.1111/j.1432-2277.2008.00780 . $\mathrm{x}$ 
82. Mayer AD, Dmitrewski J, Squifflet JP et al (1997) Multicenter randomized trial comparing tacrolimus (FK506) and cyclosporine in the prevention of renal allograft rejection: a report of the European Tacrolimus Multicenter Renal Study Group. Transplantation 64:436-443. https://doi.org/10.1097/00007 890-199708150-00012

83. Pirsch JD, Miller J, Deierhoi MH et al (1997) A comparison of tacrolimus (FK506) and cyclosporine for immunosuppression after cadaveric renal transplantation. FK506 Kidney Transplant Study Group. Transplantation 63:977-983. https://doi. org/10.1097/00007890-199704150-00013

84. Margreiter R (2002) Efficacy and safety of tacrolimus compared with ciclosporin microemulsion in renal transplantation: a randomised multicentre study. Lancet 359:741-746. https:// doi.org/10.1016/S0140-6736(02)07875-3

85. Andrews LM, Li Y, De Winter BCM et al (2017) Pharmacokinetic considerations related to therapeutic drug monitoring of tacrolimus in kidney transplant patients. Expert Opin Drug Metab Toxicol 13:1225-1236. https://doi.org/10.1080/17425 255.2017.1395413

86. Sánchez Fructuoso A, Ruiz JC, Franco A et al (2020) Effectiveness and safety of the conversion to MeltDose ${ }^{\circledR}$ extendedrelease tacrolimus from other formulations of tacrolimus in stable kidney transplant patients: a retrospective study. Clin Transplant 34:e13767. https://doi.org/10.1111/ctr.13767

87. Langone A, Steinberg SM, Gedaly R et al (2015) Switching STudy of Kidney TRansplant PAtients with Tremor to LCP-TacrO (STRATO): an open-label, multicenter, prospective phase 3b study. Clin Transplant 29:796-805. https://doi. org/10.1111/ctr.12581

88. Rifai K, Kirchner GI, Bahr MJ et al (2006) A new side effect of immunosuppression: high incidence of hearing impairment after liver transplantation. Liver Transpl 12:411-415. https:// doi.org/10.1002/1t.20610

89. Gulleroglu K, Baskin E, Bayrakci U et al (2013) Sudden hearing loss associated with tacrolimus after pediatric renal transplant. Exp Clin Transplant 11:562-564. https://doi. org/10.6002/ect.2012.0241

90. Gulleroglu K, Baskin E, Aydin E et al (2015) Hearing status in pediatric renal transplant recipients. Exp Clin Transplant 13:324 328. https://doi.org/10.6002/ect.2014.0158

91. Lakshmi BS, Vidya B, Reddy MHK et al (2020) Sensorineural deafness following tacrolimus use. Exp Clin Transplant 18:110 111. https://doi.org/10.6002/ect.2017.0114

92. Bhagavati S, Maccabee P, Muntean E, Sumrani NB (2007) Chronic sensorimotor polyneuropathy associated with tacrolimus immunosuppression in renal transplant patients: case reports. Transplant Proc 39:3465-3467. https://doi.org/10.1016/j.trans proceed.2007.06.088

93. Renard D, Gauthier T, Venetz J-P et al (2012) Late onset tacrolimus-induced life-threatening polyneuropathy in a kidney transplant recipient patient. Clin Kidney J 5:323-326. https:// doi.org/10.1093/ckj/sfs067

94. Echaniz-Laguna A, de Séze J, Chanson J-B (2012) Chronic inflammatory demyelinating polyradiculoneuropathy in solid organ transplant recipients: a prospective study. J Neurol Neurosurg Psychiatry 83:699-705. https://doi.org/10.1136/jnnp-2012302374

95. Joint Task Force of the EFNS and the PNS (2010) European Federation of Neurological Societies/Peripheral Nerve Society Guideline on management of chronic inflammatory demyelinating polyradiculoneuropathy: report of a joint task force of the European Federation of Neurological Societies and the Peripheral Nerve Society-First Revision. J Peripher Nerv Syst 15:1-9. https://doi.org/10.1111/j.1529-8027.2010.00245.x
96. Schmidt N, Alloway RR, Walsh RC et al (2012) Prospective evaluation of the toxicity profile of proteasome inhibitor-based therapy in renal transplant candidates and recipients. Transplantation 94:352-361. https://doi.org/10.1097/TP.0b013e318257acf 6

97. Fradkin M, Batash R, Elmaleh S et al (2019) Management of peripheral neuropathy induced by chemotherapy. Curr Med Chem 26:4698-4708. https://doi.org/10.2174/092986732666619 0107163756

98. Tillmann F-P, Jäger M, Blondin D et al (2008) Post-transplant distal limb syndrome: clinical diagnosis and long-term outcome in 37 renal transplant recipients. Transpl Int 21:547-553. https ://doi.org/10.1111/j.1432-2277.2008.00668.x

99. Collini A, De Bartolomeis C, Barni R et al (2006) Calcineurininhibitor induced pain syndrome after organ transplantation. Kidney Int 70:1367-1370. https://doi.org/10.1038/sj.ki.5001833

100. Mallamaci F, Zoccali C, Ciccarelli M, Briggs JD (1986) Autonomic function in uremic patients treated by hemodialysis or CAPD and in transplant patients. Clin Nephrol 25:175-180

101. Solders G, Wilczek H, Gunnarsson R et al (1987) Effects of combined pancreatic and renal transplantation on diabetic neuropathy: a two-year follow-up study. Lancet 2:1232-1235. https ://doi.org/10.1016/s0140-6736(87)91851-4

102. Solders G, Persson A, Wilczek H (1986) Autonomic system dysfunction and polyneuropathy in nondiabetic uremia. A oneyear follow-up study after renal transplantation. Transplantation 41:616-619. https://doi.org/10.1097/00007890-19860 5000-00013

103. Robinson TG, Carr SJ (2002) Cardiovascular autonomic dysfunction in uremia. Kidney Int 62:1921-1932. https://doi.org/10.104 6/j.1523-1755.2002.00659.x

104. Minetto MA, D’Angelo V, Arvat E, Kesari S (2018) Diagnostic work-up in steroid myopathy. Endocrine 60:219-223. https://doi. org/10.1007/s12020-017-1472-5

105. Townamchai N, Safa K, Chandraker A (2013) Immunologic monitoring in kidney transplant recipients. Kidney Res Clin Pract 32:52-61. https://doi.org/10.1016/j.krcp.2013.04.002

106. Li X, Ishida H, Yamaguchi Y, Tanabe K (2008) Poor graft outcome in recipients with de novo donor-specific anti-HLA antibodies after living related kidney transplantation. Transpl Int 21:1145-1152. https://doi.org/10.1111/j.1432-2277.2008.00755 . $\mathrm{X}$

107. van Besouw NM, van der Mast BJ, de Kuiper P et al (2000) Donor-specific T-cell reactivity identifies kidney transplant patients in whom immunosuppressive therapy can be safely reduced. Transplantation 70:136-143

108. Zitzner JR, Tambur AR (2012) Role of ELISPOT assays in risk assessment pre- and post-kidney transplantation. Cells 1:100 110. https://doi.org/10.3390/cells 1020100

109. Ravaioli M, Neri F, Lazzarotto T et al (2015) Immunosuppression modifications based on an immune response assay: results of a randomized, controlled trial. Transplantation 99:1625-1632. https://doi.org/10.1097/TP.0000000000000650

110. Mian M, Natori Y, Ferreira V et al (2018) Evaluation of a novel global immunity assay to predict infection in organ transplant recipients. Clin Infect Dis 66:1392-1397. https://doi. org/10.1093/cid/cix 1008

111. Doberer K, Schiemann M, Strassl R et al (2020) Torque teno virus for risk stratification of graft rejection and infection in kidney transplant recipients-a prospective observational trial. Am J Transplant 20:2081-2090. https://doi.org/10.1111/ajt.15810

112. Frasca D, Blomberg BB (2016) Inflammaging decreases adaptive and innate immune responses in mice and humans. Biogerontology 17:7-19. https://doi.org/10.1007/s10522-015-9578-8

113. Cotreau MM, von Moltke LL, Greenblatt DJ (2005) The influence of age and sex on the clearance of cytochrome P450 
3A substrates. Clin Pharmacokinet 44:33-60. https://doi. org/10.2165/00003088-200544010-00002

114. Traitanon O, Mathew JM, Shetty A et al (2019) Mechanistic analyses in kidney transplant recipients prospectively randomized to two steroid free regimen-Low dose Tacrolimus with Everolimus versus standard dose Tacrolimus with Mycophenolate Mofetil. PLoS ONE 14:e0216300. https://doi.org/10.1371/ journal.pone.0216300
Publisher's Note Springer Nature remains neutral with regard to jurisdictional claims in published maps and institutional affiliations. 